\title{
Rasch Model-Based Adversity Quotient: A Potential Instrument for Assessing Madrasah Students' Literacy
}

\author{
Akhmad Syahri ${ }^{1, *}$ Ni'matul Dinawisda ${ }^{2}$, Teguh Fachmi ${ }^{3}$ \\ ${ }^{1}$ Faculty of Tarbiya and Teachers Training, State Islamic University (UIN) Mataram, Indonesia \\ ${ }^{2}$ Postgraduate student, Indonesia University of Education (UPI) Bandung, Indonesia \\ ${ }^{3}$ Faculty of Tarbiya and Teachers Training, State Islamic University (UIN) Sultan Maulana Hasanuddin Banten, \\ Indonesia \\ "Corresponding author. Email: akhmadsyahri@uinmataram.ac.id
}

\begin{abstract}
Adversity quotient used in measuring a person's ability to respond to difficulty. Sub dimensions of adversity quotient consist of control, ownership, reach and endurance. This study aims to validate the instrument of adversity quotient for Postgraduate students by using the Rasch modelling approach that is believed to have advantages over classical test theory. This study used survey method. The data was obtained from 500 Postgraduate students. The data was analyzed by the Rasch model and assisted by Winstep software Version 3.73. The results of the study showed the instrument reliability index $(\mathrm{a}=0.82)$, with respondent reliability $(\mathrm{a}=0.79)$, and item reliability $(\mathrm{a}=0.99)$. This instrument can show $30.8 \%$ of the respondents' variance, which means it can be a guarantee of the construct validity of the instrument (item) as expected, so that it can describe the quotient of Postgraduate students in a good, accurate, and accountable manner and can be used for assessment, as well as research.
\end{abstract}

Keywords: Rasch model, Adversity quotient instrument, Literacy.

\section{INTRODUCTION}

Research on the Adversity Quotient specifically in the context of education has not been done much. Moreover, the challenges faced by students today are getting tougher, which results in many students experiencing failures in the lecture process, achieving grades that do not match expectations, being tired and bored with campus routines, and not being ready to experience feelings of disappointment, sadness, anger, shame, fear, despair, meaninglessness, low self-esteem, and other negative feelings [1].

Research on adversity quotient (AQ) can be categorized into three clusters, the first cluster is from 1997 to 2003, the second cluster is from 2004 to 2010 and the third cluster is from 2011 to the present. The subject of the adversity quotient (AQ) research in each cluster is different, in the first year the research subjects were mostly school principals, university community members, leaders, junior high school students. The second-year are undergraduate students, high school students, school principals, drug addicts, junior high school students, traders, vocational students, employees, elementary school teachers, leaders. The third-year is blind students, middle school students, principal of special needs students, disabled students, autism spectrum [2], elementary students, leaders, school administrators, young mothers, nurses, special needs teachers. From all of the research subjects, no one has examined the subject of Postgraduate students, whereas they have many roles, the more roles they have, the more challenges and difficulties they get, especially in the process of completing their studies. Postgraduate students are mature in age and maturity can manage themselves in doing all positive activities, but due to a lot of busyness, their burden is getting heavier, because they have multiple roles, namely not only studying, working, playing games (entertainment) and taking care of the family. Therefore, lecturers should understand various student problems by having management competence in the form of knowledge and skills [3], Emergency Action Plan [4], Emotion Teaching Rating Scale (EMOTERS) [5], preparation, equipment, and environment, teaching and competition, evaluation, supervision, and responsiveness in responding to emergencies [6]

The instrument in measuring adversity quotient usually uses existing instruments at learning peak.com but the situation is not experienced by the person. 
Whereas someone's problem is a real situation that is considered difficult to understand by others so that the difficulties for each person is different. So that measuring adversity quotient uses someone imagined situation is not appropriate. Based on the overall previous research, no one has examined adversity quotient towards Postgraduate students. Therefore, researchers made innovations to measure one's adversity quotient in Postgraduate students with more real questions that experienced by Postgraduate students.

The presence of adversity quotient measurement is to learn how to convert every difficulty into convenience to cause a positive side to someone in responding to every difficulty they experience [7], A person's problem is a real situation that is considered difficult to understand, moreover, the difficulties experienced by each person are different, so if measuring one's adversity quotient uses the imagined situation then it is not appropriate. Therefore, measuring adversity quotient using the Rasch model is considered appropriate, as the study of [8,9]. Measuring using the Rasch model is effective for future researchers, academics, and practitioners in all fields of education and higher education [10]. The Rasch model can create better and more accurate measurement instruments [11], assessment credible [12]. Therefore, researchers are interested in studying this study.

\section{METHODS}

This study aims to validate the adversity quotient instrument of postgraduate students based on the Stoltz scale using the Rasch modelling approach.

Participants in this study were all Postgraduate students of the University of Indonesia Education (UPI), as many as 1,169 . The number of research samples was 500 graduate students who were randomly selected from 33 majors.

The data analysis used the Rasch model and was assisted with Winstep software Version 3.73 developed by [13].

Participants in this study referred to equal odds of $50 / 50$ with a fault tolerance of $6 \%$, so participants in this study had a minimum of 300-500 people according to the participant size chart [14]. This study uses quota sampling concerning Postgraduate student demographics.

Psychometric devices were used by researchers include reliability at the instrument level (respondents and items), the validity of respondents and items, detection of bias on items, instrument unidimensionality, and accuracy of the number of responses used. A differential semantic scale that has seven points, $1-7$, is arranged in a continuum line where a very positive answer is located at the right end and the negative is at the left end. This is specifically on positive items. If there are negative items, then vice versa.

\section{FINDINGS}

The analyzed data were taken from 500 participants of the UPI Postgraduate student and it was included in the Winstep 3.73 software in the Windows 10 operating system. First, the relations are seen among dimensions. Only four dimensions are used to calculate the adversity quotient: control, ownership, reach, and endurance. The relationships of the four dimensions are detailed in Table 1 ,

Table 1. Relationship of postgraduate student adversity quotient with its dimensions

\begin{tabular}{|c|r|c|c|c|c|}
\hline \multicolumn{7}{|c|}{ Correlations } \\
\hline & AQ & C & 0 & $R$ & $E$ \\
\hline AQ & 1 & $.750^{* *}$ & $.716^{* *}$ & $.486^{* *}$ & $.801^{* *}$ \\
\hline
\end{tabular}

The results of the four dimensions of adversity quotient with its dimensions according to Table 1 . It shows that the endurance dimension has the highest correlation and the lowest Reach among the other three dimensions. The researchers compiled an adversity quotient instrument based on the difficulties of Postgraduate students in terms of personality, social, and learning difficulties.

Regarding the table above, the Theory of Planned Behavior explains that a person can act based on his intentions or intentions only if he has control of his behavior [15]. This theory not only emphasizes the rationality of human behavior but also on the belief that the target behavior is under the control of the individual's consciousness. A behavior depends not only on one's intentions but also on other factors that are not under the control of the individual, for example, the availability of resources and opportunities to display the behavior [16].

\subsection{Reliability of the Instrument}

The results of the instrument reliability analysis conducted with Winstep obtained information that the amount of data provided by 500 participants with 50 items of adversity quotient, the instruments were 24,992 data. The Chi-square value was 84595.42 with a degree of freedom (d.f) of 24438 ( $p=0,000$ and $p$ 0.01). This shows that overall, the measurements made are very good and the results are significant. The results of this analysis contain two outputs, namely the output of the respondent (person) and the output of the item. The respondent table explains, in general, whether or not the respondent is used. Likewise, the item in the table explains whether, in general, the items used in the instrument can be fitted or not. Referring to Ta2 below, the average measured value obtained from the Person table is $11.68(\mu>0.00)$. This shows that in general, respondents have high adversity 
quotient scores, in the sense that respondents tend to approve items that measure indicators of adversity quotient. A logit value of 11.68 also indicates that respondents have a large diversity in the measured constructs. This happens because respondents come from different demographic settings, namely gender, age, regional origin, university origin, majors, tuition payment status, employment status, and marital status. Detailed, reliable information is in the table. 2 of the following,

Table 2. Instrument reliability

\begin{tabular}{|c|r|r|r|c|}
\hline & $\begin{array}{c}\text { Logit } \\
\text { Average }\end{array}$ & Separation & Reliability & $\begin{array}{c}\text { Alpha } \\
\text { Cronbach }\end{array}$ \\
\hline Person & 0,24 & 1,94 & 0,79 & 0,82 \\
\hline Item & 0,00 & 11,12 & 0,99 & \\
\hline
\end{tabular}

Note: The data in the table above is taken from the summary statistics of 500 measured people and a summary of 50 measured items.

Cronbach's alpha value (KR-20), which measures the interaction between respondents and items, shows good results, namely $\alpha=0.82$. The reliability, value for the respondents obtained based on Table 3 above is 0.82 . This shows the suitability between respondents and the instruments used. Besides, the reliability value of items is 0.99 , which indicates that the instrument has very good reliability $(\alpha>0.94)$ [11] Based on the evaluation of the psychometric property, the actual data obtained is per the conditions of the Rasch model, so that further analysis can be applied.

\subsection{Validity of Respondents and Items}

There are efforts to examine respondents and items that are not appropriate (outliers or misfits) [11]. I suggest three criteria:

1. The received Outfit Mean Square (MNSQ) values are 0.5 MNSQ 1.5.
2. The Outfit Z-Standard (ZSTD) received is:-2.0 $<$ ZSTD $<+2.0$.

3. The value of Point Measure Correlation (PT Mean Corr) received is: $0.4<\mathrm{PT}$ Measure Corr $<0.85$.

The results of the Fit/Misfit Test respondents addressed 37 , or $7.25 \%$, of the participants who had inconsistent answers. In the context of analysis with inferential statistics, it is recommended that misfit respondents be eliminated. For the fit/misfit item analysis, three criteria as previously stated were used. However, the criteria for item elimination are based on the results of the analysis which are convinced that the items are not consistent, namely two of the three criteria above, one of which is a negative Point Measure Correlation value. The average logit value of the item is 0.0 . This shows that, overall, the instrument can measure what it is the objective of measuring. The mean value of the 0.0 logit item is a random value that is set to express the possibility of 50:50 as an equivalent measure between the level of respondent's ability and item difficulty [17]. The item of Fit / Misfit Test Results addresses item No. 29 Outfit MNSQ = $1.75(>1.5)$ and ZSTD = $9.9(>2.0)$ and PT Measure Correlation $=-0.07(<0.4)$. However, for this item, it is still recommended that editorial improvements can be made.

\subsection{Instrument Unidimensionality}

In this case, it is a construct of fundamentalism in the individual. The Rasch model analysis uses Principal Component Analysis of residuals, which measures the extent to which the diversity of instruments, measures what should be measured [17].

Based on Table 3 above, it can be seen that the raw variance measurement results are $30.8 \%$. The value is not much different when compared to the expected value of $31.9 \%$. The unidimensional limit in the Rasch model of $40 \%$ was also met [17]. Another thing that is also supported is that the variances that cannot be explained

by the

Table 3. Instrument unidimensional test results

\begin{tabular}{|l|r|r|r|r|}
\hline & & Empirical & & Modeled \\
\hline Total raw variance in observations $=$ & 722.3 & $100.0 \%$ & & $100.0 \%$ \\
\hline Raw variance explained by measures $=$ & 222.3 & $30.8 \%$ & & $31.9 \%$ \\
\hline Raw variance explained by persons = & 24.7 & $3.4 \%$ & & $3.5 \%$ \\
\hline Raw variance explained by items $=$ & 197.6 & $27.4 \%$ & & $28.4 \%$ \\
\hline Raw unexplained variance (total) $=$ & 500.0 & $69.2 \%$ & $100.0 \%$ & $68.1 \%$ \\
\hline Unexplained variance in 1st contrast $=$ & 48.4 & $6.7 \%$ & $9.7 \%$ & \\
\hline Unexplained variance in 2nd contrast $=$ & 35.7 & $4.9 \%$ & $7.1 \%$ & \\
\hline Unexplained variance in 3rd contrast $=$ & 25.6 & $3.5 \%$ & $5.1 \%$ & \\
\hline Unexplained variance in 4th contrast $=$ & 21.7 & $3.0 \%$ & $4.3 \%$ & \\
\hline Unexplained variance in 5th contrast $=$ & 19.3 & $2.7 \%$ & $3.9 \%$ & \\
\hline
\end{tabular}


instrument are all below 10\%. This shows that the level of independence of the items in the instrument is included in either category.

\subsection{Validity of a Ranking Scale}

Ranking scale validity is a test conducted to verify whether the choice of ranking used is confusing for respondents or not. The analysis of the Rasch model provides a verification process for the ranking assumptions given in the instrument. In this instrument, 7 alternative answers are given. The answers move from one to seven, one representing at least the individual self and increasing to seven at best describing the individual. As can be seen in Figure 1.

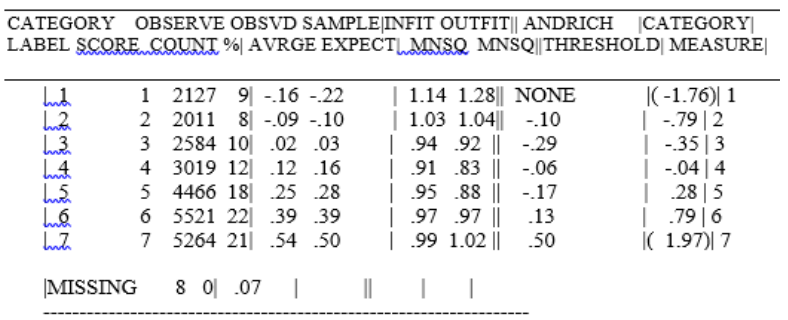

Figure 1 The validity of the ranking scale

In Figure 1, it can be seen that the average observation starts from logit-0.16 for option 1 and increases to logit 0.54 for choice 7 . Increasing the value of the logit shows consistent results. This shows that the ranking scale 1-7 can be said not to be confused for respondents and is an appropriate scaling range of this instrument. Another recommended measure is the Andrich Threshold, which tests whether the political values used are correct or not. The Andrich Threshold value that moves from NONE to negative and leads to positive sequentially shows that the five options given are valid for respondents. This corresponds to the minimum and maximum range, which is between 1.40 to 5.0 .

\section{RESULTS AND DISCUSSION}

The results of the evaluation of this research instrument showed the value of alpha Cronbach reliability (KR-20) of 0.82 and item reliability of 0.99 provided empirical support for the quality of adversity quotient measurement. However, information was also obtained related to items that should be eliminated. It was item 21. This item was deemed inappropriate because it contained a bias that is "my IP is low because the lecturer is favoritism towards colleagues". Whereas based on the fit/misfit item test, the editorial improvement recommendations also apply to item 21. The map variable also shows that the value of adversity quotient shows an even distribution, both by gender and other demographics, so that the ability of Postgraduate students to solve problems encountered during college can be measured by this instrument. This can be used as an indicator of the development of the adversity quotient in UPI. Postgraduate students are influenced by a variety of complex variables. The instrument unidimensionality test results showed that the measurements made were able to explain $30.8 \%$ of the variance of respondents. It functioned as a unidimensional measure with good internal consistency reliability [18]. This can be a guarantee that the validity of the instrument extracts is as expected.

The findings and results of the research above are in line with previous studies that the adversity quotient (AQ) instrument from Stoltz is widely used by researchers from all over the world.

The number of completed studies was 40 from 2000 to 2016 and there are 34 ongoing studies. Some researchers are on the web and others are [19-42], these researchers were only fixated on the concept of validation explained by Stoltz on their website or they just use validity using the SPSS application, no one had used the Rasch model application. While the Rasch model can see the interaction of respondents and items at the same time. Therefore, validity needs to be developed using the Rasch model [43]. For example, the Rasch model developed by Andrich is used for political data based on two basic theorems, namely the level of ability/agreement of individuals and the level of difficulty of items to be approved [17]. Likewise, the results of research by [44], that showed the items' difficulty level was generally moderate and suitable for the scale's intended populations and purposes when using the Rasch model. The Rasch model can provide better measurement properties even though it is based on demographic factors [45].

The Rasch model is one of the modern test theory methods that assesses the extent to which rigorous measurement is achieved [46]. In the Rasch model, in the process of analysis, raw data cannot be directly analyzed, but must first be converted into odds ratios to convert logarithms into logit units that can manifest the probability of respondents to respond to an item. Reference [11] mention that the Rasch model can be used as a method of returning data according to its initial conditions naturally. This natural condition refers to the basic characteristics of quantitative data, which is ongoing. Through the Rasch model, the ordinal response can be transformed into interval data which has a higher level of accuracy by referring to the principle of probability. Reference [47] emphasizes five important parts in the analysis using the Rasch model, namely calibration and item estimation ability, interaction map between items and respondents, item/respondent fit/misfit, item and instrument information functions, and item curve characteristics in the model parameterized.

Other studies [48-49] stated the same findings as to the results of this study, that analysis using the Rasch 
model measurement has shown that 54 items meet the criteria of item fit, unidimensionality, and reliability index. It has shown a valid item match index. The analysis shows the strength of psychometric properties which include aspects of validity and reliability. This finding also has implications for theory, with empirical evidence related to student and youth profiles.

Based on the overall previous research, no one has examined the adversity quotient towards Postgraduate students. Therefore, researchers made innovations to measure one's adversity quotient in Postgraduate students with more real questions than experienced by Postgraduate students

\section{CONCLUSION}

The results of the analysis from the developed instrument data can be used as empirical support for measuring instruments of adversity quotient based on good psychometric guarantees, as the results of the study show the instrument reliability index $(a=0.82)$, with respondent reliability $(\mathrm{a}=0.79)$, and item reliability $(\mathrm{a}=$ 0.99). This instrument can show $30.8 \%$ of the respondents' variance, which means it can be a guarantee of the construct validity of the instrument (item) as expected, so that it can describe the quotient of Postgraduate students in a good, accurate, and accountable manner and can be used for assessment, as well as research.

Notwithstanding the positive result above, there is a limitation in this study that is should be noted, namely, the issues of culture and diversity are not addressed in the current framework of adversity question. Future research should include a more comprehensive evaluation of the scale.

\section{AUTHORS' CONTRIBUTIONS}

All authors have different roles in the accomplishment of the study. For this manuscript, they contributed equally to the process of drafting, revision, and approval of the final revision.

\section{REFERENCES}

[1] Hutasoit, Repository, 2009. URL: https://uksw.wdu/ bitstream/123456789/4861/2/T1_13201060_BAB I.Pdf

[2] W. Yan, et al., Psychometric properties of the Chinese Parent Version of the Autism Spectrum Rating Scale: Rasch analysis, Autism, (2021) 1-13. DOI: https://doi.org/10.1177/13623613211004054

[3] Bafirman, Influence of sport, physical education and healt teacher professionalism in developing students' character, Asian Social Science 10(5)
(2014) 7-11. DOI:

https://doi.org/10.5539/ass.v10n5p7

[4] ACICR., Safety Guidelines for Physical Activity in Alberta Schools, Canada: Alberta Center for Injury Center and Research, 2013.

[5] R. A. Gordon, et al., An introduction to the manyfacet Rasch model as a method to improve observational quality measures with an application to measuring the teaching of emotion skills, Early Childhood Research Quarterly 55(2) (2021) 149164.

DOI:

https://doi.org/10.1016/j.ecresq.2020.11.005

[6] A. bin Esa, F. Mustaffa, Instrument development sports risk management practice using Rasch measurement model, Canadian Center of Science and Education (Asian Social Science) 11(18) (2015). DOI: https://doi.org/10.5539/ass.v1In18p18

[7] P. G. Stoltz, E. Weihenmayer, The Adversity Advantage: Turning Everday Struggles into Everyday Greatness (2nd ed), New York: Fireside, 2010.

[8] Mohd. Effendi, A. Zamri, Correlation between AQ with IQ, EQ, and SQ among Polytechnic Students in Malasyia using Rash model, Indian Journal of Science and Technology 9(47) (2016) 1-8. DOI: https://dx.doi.org/10.17485/ijst/2016/v9i47/108695

[9] Mohd. Effendi, A. Zamri, Nordin, The influence of AQ on the academic achievement among Malasian Polytechnic Students, 74 (2015). DOI: https://doi.org/10.5539/ies.v8n6p69

[10] A. Y. M. A. Islam, et al., Assessment of ICT in Tertiary Education Applying Structural Equation Modeling and Rasch Model, Journals Sagepub, (2020) 1-17. DOI: https://doi.org/10.1177/2158244020975409

[11] Sumintono, Bambang, W. Widhiarso, Aplikasi Model Rasch untuk Penelitian Ilmu-ilmu Sosial, Cimahi: Trim Komunikata Publishing House, 2014.

[12] J. Mi Scoulas, et al., Validating students' library experience survey using rasch model, Library and Information Science Research, 43 (2021) 101071. DOI: https://doi.org/10.1016/j.lisr.2021.101071

[13] J. M. Linacre, A user's guide to winstep ministep rasch-model computer programme, 2006. URL: www.winstep.com

[14] J. W. Creswell, Research Design Pendekatan Kualitatif, Kuantitattif, dan Mixed, Yogyakarta: Pustaka Pelajar, 2012.

[15]I. Ajzen, From intentions to actions: A theory of planned behavior, in: J. Kuhl, J. Beckmann (Eds.), 
Action Control, Cognition to Behavior, SpringerVerlag, New York, NY, 2002, pp. 11.

[16]I. Ajzen, The theory of planned behavior, Organizational Behavior and Human Decision Process 50(2) (1991) 179-211. DOI: https://doi.org/10.1016/0749-5978(91)90020-T

[17]I. H. Misbah, B. Sumintono, Pengembangan dan validasi instrument persepsi siswa terhadap karakter moral guru di Indonesia dengan model Rasch, in: Seminar Nasional "Pengembangan Instrumen Penilaian Karakter yang Valid" di Fakultas Psikologi, Universitas Muhammadiyah Surakarta, 2014.

[18]E. Teye-Kwadjo, G. P. de Bruin, Rasch analysis of the proactive personality scale, Psychological Reports (2021) 1-21. DOI: https://doi.org/10.1177/00332941211028110

[19] Abejo, The adversity quotient profile of 39 out of 74 employees of the college of arts and sciences of st. joseph's college in quezon city for the school year 2001-2002 as indicator of their effectiveness as leaders. Quezon: St. Joseph's college, Peaklearning, 2002.

[20]Z. Huijuan, The adversity quotient and academic performance among college students at St. Joseph's college, quezon city. Undergraduate thesis, the departments of arts and sciences St. Joseph's College Quezon city, Peaklearning, 2009.

[21]P. Sachdev, Effectiveness of an intervention programme to develop adversity quotient of potential leaders, Peaklearning, 2009.

[22] S. Tripathi, Use of Adversity Quotient ${ }^{\circledR}\left(\mathrm{aq}{ }^{\circledR}\right)$ in Creating Strong Business Leaders of Tomorrow, Peaklearning, 2011.

[23] V. R. S. Alka, A study of secondary school students' response to adversity in relation to certain psychological and performance factors, 2012.

[24]F. O. Bantang, et al., The relationship of personal characteristics and job satisfaction to adversity quotient of police officers in manila police district, Peaklearning, 2013.

[25] J. N. Napire, Adversity quotient ${ }^{\circledR}$ and leadership style in relation to the demographic profile of the elementary school principals in the second congressional district of camarines sur, Peaklearning, 2013.

[26] G. A. Cornista, C. J. Macasaet, Adversity quotient and achievement motivation of selected third year and fourth year psychologis students of de la salle lipa a.y. 2012-2013 (thesis), The faculty of the college of education, arts, and sciences de la salle lipa, Peaklearning, 2013.

[27]X. M. Gulan, Adversity quotient and openness to group diversity as predictors of job embeddedness, Peaklearning, 2013.

[28] V. B. Nikam, M. M. Uplane, Adversity quotient and defense mechanism of secondary school students, Universal Journal of Educational Research, 1(4) (2013) 303-308.

[29] Y. T. X. Fan, Adversity quotients, environmental variables and career adaptability in student nurses, Journal of Vocational Behavior, 85(3) (2014) 251257.

[30] M. Devakumar, A study of adversity quotient of secondary school students in relation to their academic self-concept and achievement motivation, Peaklearning, 2014.

[31]M. J. O. Daloos, Emotional intelligence and adversity quotient of selected helping professionals, Peaklearning, 2015.

[32]B. M. Bakare, Students' adversity quotient and related factors as predictors of academic achievement in the west african senior school certificate examination in southwestern Nigeria, Peaklearningz, 2015.

[33]E. D. Baroa, Adversity quotient and leadership skills of school administrators: basis for program enhancement, Peaklearning, 2015.

[34]G. Hema, M. G. Sanjay, Adversity quotient for prospective higher education, The International Journal of Indian Psychology 2(3) (2015).

[35]L. Harriman, Measuring millennials' adversity quotient and its correlation with individual performance in project teams, Peaklearning, 2016.

[36] M. V. B. Ablana, J. I. Danica, Correlation between adversity quotient ${ }^{\circledR}$ and job performance of lgu employees of tayabas city: Input to effective public personnel management, Peaklearning, 2016.

[37] A. M. Maureen, The level of adversity quotient ${ }^{\circledR}$ and social skills of student leaders at de la salle lipa, Peaklearning, 2016.

[38] J. C. Rafols, Profile, adversity quotient ${ }^{\circledR}$, and multifactor leadership characteristics of student affairs and services administrators: Towards a leadership management training design, Peaklearning, 2015.

[39] R. R. Villagonzalo, Intelligence quotient, emotional quotient, spiritual quotient, and adversity quotient ${ }^{\circledR}$ and the academic performance of students, Peaklearning, 2016. 
[40] V. C. Patdo, et al., The adversity quotient of parents with special children and adversity quotient of parents with normal children, Peaklearning, 2011.

[41]L. Sausa, et al., Predictive ability of emotional intelligence and adversity quotient on academic performance of usc college students, Philippines, Peaklearning, 2015.

[42]E. L. Villaver, The adversity quotient levels of female grade school teachers of a public and a private school in rizal province, Peaklearning, 2005.

[43]L. Danielsson, et al., Development and construct validity of the work instability scale for people with common mental disorders in a sample of depressed and anxious workers: A Rasch analysis, Rehabilitation Process and Outcome 9 (2020) 1-10. DOI: https://doi.org/10.1177/1179572720936664

[44] P. J. Silvia, et.al., Measuring everyday creativity: A Rasch model analysis of the Biographical Inventory of Creative Behaviors (BICB) scale. Thinking Skills and Creativity 39 (2021) 100797. DOI: https://doi.org/10.1016/j.tsc.2021.100797

[45]Z. L. Msc, et al., Evaluation of the structural validity of the work instability scale using the Rasch model, Archives of Rehabilitation Research and Clinical Translation 3(1) (2021) 100103. DOI: https://doi.org/10.1016/j.arrct.2021.100103

[46]E. Villalonga-Olives, et al., Rasch model of the bridging social capital questionnaire, SSM Population Health 14 (2021) 100791. DOI: https://doi.org/10.1016/j.ssmph.2021.100791

[47] H. Y. Chong, A simple guide to the item response theory (IRT) and rasch modelling, 2013. URL: http://www.creative-wisdom.com

[48] K. Miftahuljannah, M. E. E. M. Matore, Development and Validation of Psychometric Properties of The 10 IB Learner Profile Instrument (10IBLP-I): A Combination of the Rasch and Classical Measurement Model, International Journal of Environmental Research and Public Health (IJERPH) 18 (2021) 6455. DOI: https://doi.org/10.3390/ijerph18126455

[49] M. E. E. M. Matore, et al., The Development and Psychometric Assessment of Malaysian Youth Adversity Quotient Instrument (MY-AQi) by Combining Rasch Model and Confirmatory Factor Analysis, IEEE Acces 9 (2021). DOI: https://doi.org/10.1109/ACCESS.2021.3050311 